\title{
BESLENMEDE FARKINDALIK
}

\author{
Y. Birol Sayg1 ${ }^{*}$, Irmak Sayg1 $^{2}$ \\ 1) Bahçeşehir Üniversitesi, Uygulamalı Bilimler Yüksekokulu, Gastronomi ve Mutfak Sanatları Bölümü, İstanbul, \\ Türkiye \\ 2) Brunel University London College of Health, Medicine and Life Sciences \\ Post-Graduate Studies, London, UK
}

Geliş / Received: 02.08.2021; Kabul / Accepted: 12.12.2021; Online bask1 / Published online: 18.12.2021

Sayg1, Y.B., Sayg1, I. (2021). Beslenmede farkındalık. GIDA (2021) 46 (6) 1494-1504 doi: 10.15237/ gida.GD21109.

Saygl, Y.B., Saygl, I. (2021). Mindful Eating. GIDA (2021) 46 (6) 1494-1504 doi: 10.15237/gida.GD21109.

\section{ÖZ}

Farkındalık, kişinin mevcut deneyimine tam dikkat ve farkındalık getirme kapasitesidir. Beslenmede farkındalık yemek seçimine ve yemek yeme deneyimine dikkat getirir. Bugün, farkındalık ve buna yardımcı teknikler günlük hayattaki binlerce insanın depresyon, kronik kayg1 gibi klinik problemlerin yanında problem çözme, duygu regülasyonu gibi sıklıkla karşlaşılan ruhsal ve bilişsel sorunlarla baş etmesine yardımcı olarak kişilerin daha ana odaklı ve bilinçli şekilde yaşamasına yardımcı olmuştur. Yemek insanoğlunun yaşamını sürdürmesi için gereken en temel unsurlardan biridir ve beslenme bütün canlılar için günlük rutinin ayrilmaz bir parçasıdır. Bu bağlamda da farkındalık durumunun beslenmeyi etkilemesi, aynı şekilde beslenmenin farkındalı̆̆ arttıracak tekniklerde kullanılabilmesi kaçınılmazdır. Buna bağlı ortaya çıkabilecek sorular beslenmede farkındalı̆̆ın kökeni, kişi üzerinde etkileri ve uygulamalarını kapsamaktadır. Söz konusu çalışma güncel verilerle bu bağlamı ve oluşabilecek soruları aydınlatmayı amaçlamıştır.

Anahtar kelimeler: Farkındalık, beslenmede farkındalık, beslenme alışkanlıkları, psikolojik yaklaşımlar

\section{MINDFUL EATING}

\begin{abstract}
Mindfulness is the capacity to bring full attention and awareness to one's current experience. Correspondingly, Mindful eating brings attention to food choice and eating experience. Today, mindfulness and its assistive techniques have helped thousands of people, including the clinical population, in their daily lives to cope with clinical problems such as depression and chronic anxiety, as well as frequently encountered mental and cognitive problems such as problem solving and emotion regulation in addition to helping people to live more focused and consciously. Food is one of the most basic elements required for the survival of human beings, and nutrition is an integral part of the daily routine for all living things. In this context, it is inevitable that the mindfulness affects food choices and eating habits as well as the food's role on mindfulness meditations which can increase awareness. Due to this fact, the arise of the questions regarding the origins, effects and applications of mindful eating become inevidable. Therefore, this aforementioned study aimed to clarify this concept and related questions based on the latest findings.
\end{abstract}

Keywords: Mindfulness, mindful eating, eating habits, psychological approaches

\footnotetext{
*Yazışmalardan sorumlu yazar / Corresponding author

$\varangle$ : yasarbirol.saygi@sad.bau.edu.tr
}

留: (+90) 5322949857

Y. Birol SaygI; ORCID no: 0000-0001-9829-960X

Irmak Saygl; ORCID no: 0000-0002-8051-7987 


\section{FARKINDALIK}

\section{Farkındalığın Kökeni}

Bugün yaygın olarak İngilizce karşıllı̆ı olan Mindfulness tercih edilse de Türkçe ismiyle ÖzFarkındalık, Bilinçli Farkındalık ya da Farkındalık, kavram olarak kökenini Budizm'den alır. Buna göre de Pali dilindeki karşllığ Sampajañña'dır. Bu kavram yine Pali dilindeki sati (farkındalık) ve samprajanya (açı, temiz algilama) kelimelerinin birleşiminden türetilmiştir (Schuman-Olivier vd., 2020). Farkındalık geleneksel anlamıla kişinin dikkatini şimdiki anda toplayarak kendi benliğindeki ve benliğinin dişındaki durumları yargilamaksızın kabullenebilme kapasitesini işaret eder (Grecucci vd., 2015). Bununla birlikte Farkındalık meditasyonlanı olarak bilinen bir kısım uygulama da bu farkındalı̆̆ arttırmak için geçmişten bugüne kullanılmaktadır. Tekrardan not edilmelidir ki farkındalık zihinsel bir durumdur, farkındalık uygulamaları ya da meditasyonları zihni bu duruma getirmeye ya da bu durumu arttırmaya yarayan tekniklere denmektedir. $\mathrm{Bu}$ noktada beslenmede farkındalığın sezgisel yeme (intuitive eating) ile karıştırılmaması önemlidir. Sezgisel yeme resmi olarak 1995 yilında iki diyetisyen tarafindan ortaya konmuş bir kavramdır ve diyetlere başka bir ifadeyle gıdaları iyi, kötü diye etiketlemeye karşı çıkan yaklaşımı ifade eder. Bu kapsamda da beslenme için kişilerin odağının temelde açlık ve tokluk duyguları üzerine çevrilmesi gerektiğini belirtir. Beslemede farkindalikla karşılaştırıldığında her iki yaklaşımda da kişinin mevcut beslenmeyle bağıntilı bedensel algisına odaklanmak unsur olarak öne çıksa da sezgisel yeme kapsaminda beslenmede farkındalıkta olduğu gibi kendisiyle özdeşleşmiş bir teknik, uygulama veya meditasyon barındirmaz (Kerin vd., 2019; Warren vd., 2017).

Kökeni eski olsa da farkındalık bugünkü popülerliğini çoğunlukla Farkındalık Bazlı Stres Azaltma (MBSR) ve Farkındalık Tabanlı Bilişsel Terapi (MBCT) programlarının geliştiricisi Prof. Dr. Jon Kabat-Zinn'e borçludur (Kabat-Zinn, 1991; Wielgosz vd., 2019). Kabat-Zinn'in çalışmaları halk popülerliğinin ötesinde Farkındalık kavramının psikoloji literatüründe yer alması açısından önemlidir. Başta Kabat-Zinn’in çalışmalarını yürüttüğü Massachusetts Teknoloji Üniversitesi olmak üzere bugün Oxford ve Harvard Üniversiteleri dahil pek çok üniversitenin bilimsel olarak Farkındalık üzerine çalışan spesifik bölümleri mevcuttur.

\section{Farkındalığa Psikolojik Yaklaşımlar}

Bununla birlikte literatürde de farkındalık kavramına farklı yaklaşımlar söz konusudur (Çizelge 1). Bunlardan biri Kabat-Zinn'in kavramın geleneksel kökenlerine uygun pasif yaklaşımında Farkındalık terimi, belirli bir şekilde bilinçli olarak mevcut anda ve yargisız olarak dikkat etmek" olarak tanımlanmıştır. Buna karşılık Harvard Üniversitesi'nden Prof. Dr. Ellen Langer'ın öncülüğünde farkındalığa aktif yaklaşım mevcuttur. Langer, Farkındalığı Mindlessness (kişinin kendindeki ve çevresindeki durumlara karşı bilinçsizliği) durumunun aksi olarak şimdiki anın tamamen farkında, ona dahil olduğumuz ve değişiklikleri de fark etmeye açı olduğumuz esnek bir zihinsel durum olarak tanımlar (Langer, 2000). Langer'in tanımındaki aktiflik dikkatin anın farkında olabilmek adına mevcut bir duruma aktif olarak yönlendirilmesi, başka bir ifadeyle farkındalığın bir araç olarak kullanılması gerekliliğinden gelir. Buna rağmen, Gelenek ve Kabat-Zinn mevcut durumların herhangi birine odaklanmadan hepsini yargisizca kabullenmeyi işaret eder (Compton ve Hoffman, 2018).

\section{Farkındalığın Kişilere Etkileri}

Farkındalık hali nedir ve farkındalık uygulamaları ne işe yarar, nasıl çalışır? Farkındalık zihinsel bir durumu ifade ettiğinden deneyimseldir ve kavramsal olarak açıklamak oldukça zordur. Bilişsel olarak farkındalık pasif yaklaşımla kişilerin çevresindekileri yargılamadan kabul etmesini sağlar. Odağın şimdiki çevrede olması dikkatin anda toplanmasına geçmişin ve geleceğin yarattığ stres ve kayg1yı azaltarak şu anın keyfine varabilmeye yardımcı olur. Aktif yaklaşımın da amacı aynıdır. Fakat bu yaklaşımda dikkati anda toplayabilmek için kişinin andaki bir varlık veya durumla etkileşmesini gereklilik koşar.

Farkındalığın, özellikle farkındalı̆ga dair tekniklerin psikolojik müdahale (intervention) olarak uygulandiğ1 deneyler sonucunda 
katılımcılarda görünen bilişsel yansımalarını başlıca kişi raporlarından almak mümkündür. Bununla birlikte son ylllardaki nörobilim çalışmaları da bu konuda literatüre önemli katk1larda bulunmuştur. Örnek olarak 2012 yllında Harvard Üniversitesi Tip Fakültesi'nden Prof. Dr. Gaelle Desbordes ve arkadaşlanı tarafindan fonksiyonel manyetik rezonans görüntüleme (fMRI) kullanılarak gerçekleştirilen çalışma göstermiştir ki iki aylık farkındalık meditasyonu eğitimi alan katılımcıların öncesi ve sonrası görüntülemelerinde katılımcılara duygusal yoğunluktaki resimler sunulduğunda beyinde duyguların işlenmesinde temel bir rol oynayan amigdalanın aktivitesinde önemli bir azalma görülmüştür (Powell, 2018). Bunu 2018 yilında takip eden Prof. Dr. Benjamin Shapero ve meslektaşları tarafindan gerçekleştirilen 12 depresyon hastası üzerinde gerçekleştirilen ve Kabat-Zinn tarafindan geliştiren Farkındalık Tabanlı Bilisssel Terapi (MBCT)'nin etkisini araştıran başka bir çalışmada da sadece amigdalaya bağlı streste değil, katılımcıların bilişsel, ruhsal ve nöral mekanizmalarında da iyileşme gözlendiğini rapor etmiştir. Ek olarak, farkındalık uygulamalarının, katılımciların raporlarıyla fMRI'ları (beyinde utanç gibi düşüncesel geliştirilmiş duyguların regülasyonunda önemli rol oynayan anterior singulat korteksin aktivitesi) incelendiğinde 'beyinde sessizleşme' denilebilecek, spekülatif olarak faydalı bir etkisi bulunmuştur (Deliperi vd., 2011).

Cizelge 1. Farkındalığa (Mindfulness) psikolojik yaklaşımlar

\begin{tabular}{|c|l|}
\hline Pasif Yaklaşım & Aktif Yaklaşım \\
\hline - Her iki yaklaşım için de farkındalı öğrenebilen bir beceri olarak tanımlanır. \\
- Her iki yaklaşım için odak mevcut andadır.
\end{tabular}

\section{BESLENMEDE FARKLILIK}

\section{Beslenmede Farkındalığın Kökeni}

Farkındalık, dikkati şimdiye yöneltmeyi gerektirdiğinden günlük hayatın kaçınılmaz bir parçasıdır ve etkileri de yine günlük hayatta gözlemlenebilir. Bugün, farkındalık ve buna yardımc1 teknikler günlük hayattaki binlerce insanın depresyon, kronik kaygı gibi klinik problemlerin yanında problem çözme, duygu regülasyonu gibi sıklıkla karşılaşılan ruhsal ve bilişsel sorunlarla baş etmesine yardımcı olarak kişilerin daha ana odaklı ve bilinçli şekilde yaşamasına yardımcı olmuştur. Yemek insanoğlunun yaşamını sürdürmesi için gereken en temel unsurlardan biridir ve beslenme bütün canlılar için günlük rutinin ayrılmaz bir parçasıdır. $\mathrm{Bu}$ bağlamda da farkındalık durumunun beslenmeyi etkilemesi, aynı şekilde beslenmenin farkındalığ1 arttıracak tekniklerde kullanılabilmesi kaçınılmazdır. Literatürde beslenmede farkındalığın ilk kez 90’ların sonunda Kristeller ve Hallet'in Farkındalık Tabanlı Beslenme Terapisi (MB-EAT)'nin Tikanırcasına Yeme Bozukluğu (Binge Eating Disorder) teşhisi konmuş obeziteli kadınlar üzerine etkisini araştırmasında karşılaşııır (Burton. 2020; Ives-Deliperi vd. 2011; Kristeller, 2015; Warren vd., 2017).

\section{Beslenmede Farkındalığa Psikolojik Yaklaşımların Uygulanması}

Bahsedildiği üzere, farkındalıkta pasif ve aktif yaklaşımlarının her ikisinin de merkezinin şimdi olmasının yanında aktif yaklaşım günlük durum ve objelerle etkileşimi gerektirir. Bu kapsamda beslenme farkındalıkta iki şekilde yer alabilir. İlk olarak beslenmede farkındalığa, genel farkındalığa 
uygun nitelikte zihinsel bir durum olarak ulaşmaktan söz edilebilir. Bu zihinsel durum da kişinin duyusal ve bilişsel deneyimlerine odaklanarak (pasif yaklaşımda yargılamadan) andaki beslenmesine olan yaklaşımına denk gelmektedir. İkinci olarak aktif yaklaşımda gıdaların, farkındalığı arttırmak için bir araç; yemek yemenin de farkındalığ1 arttıracak bir teknik olarak kullanılması ön plandadır. Bu kapsamda da şimdideki gidayla ve yemek yeme aktivitesiyle etkileşim farkındalık durumuna erişebilmek için gereklidir.

Gidalar ve beslenme aktivitesi genel olarak duyusal değerlendirme parametreleri çerçevesinde bir deneyimdir. Bütün bu duyular gıdayla ilgili kişinin anılarını ve beklentilerini kapsayan algının devreye girerek bilişsel olarak beslenmeyi neredeyse önceden belirlenmiş hale getirir. Başka bir ifadeyle gıdayı tüketirken alınan tadın büyük bir kısmı daha öncesinde bu gidaya dair hafizada kaydedilmiş duyumlardan alınan ve beyin tarafindan yorumlanmış verilerden gelir. $\mathrm{Bu}$ evrimsel bir savunma mekanizması olup kişinin sevdiği ve "güvenli" gördüğü gıdaları yemeye devam edip, sevmediği ve "güvenmediği" gidalardan kaçınmasını sağlamaktadır. Beslenmede farkındalık, bu çerçevede bu alg1yı kırmayı amaçlamaktadır. Detaylandırılırsa, beslenmede dikkati andaki duyumlara odaklayarak mevcut gidaya yönelik anlık veri almak ve bu yolla kişi örnek olarak bir elmayı yerken bunu öncekilerden kalan verileri eleyerek söz konusu elmanın farkına varabilmeyi ve bunu takdir edebilmeyi amaçlar (Hong vd., 2011). Ayrıca pasif yaklaşımda olduğu üzere deneyimi yargilamamak bahsedilen ilkel savunma mekanizmasının etkisini azaltarak daha önceden sevilmeyen bir gidaya dair tercihleri tekrar değerlendirmek gibi beyinde bir takım bilinçli aktiviteye aracılık eder.

\section{Farkında Olmadan (Mindless) Beslenme}

Beslenmede farkındalık literatürde ve popüler kültürde aktif yaklaşıma uygun olarak daha çok farkındalık durumuna ulaşmaya yardımcı bir teknik olarak kullanımı incelenmiştir. Bununla birlikte aktif farkındalı̆̆ın savunucusu Langer için farkındalık (mindfulness), farkında olmama (mindlessness) durumunun karşısındadır. Bugün beslenmede farkındalık açısından farkında olmama durumunun literatürde çeşitli karşıllıklar bulabilmektedir.

Bunlar içinde en bilinenlerden biri Türkçede tıkanırcasına yeme bozukluğu (TYB) olarak bilenen psikolojik rahatsızlıktır. TYB, kendini sık ve sürekli yeme nöbetleriyle gösteren aşırı miktarda gida tüketimini içeren ve yeme üzerinde kontrol azlığı gibi bağımlılık ile örtüşen özellikleri bulunan bir psikolojik rahatsızlıktır. Amerikan Psikiyatri Derneği (American Psychiatric Association, APA) tarafindan Ruhsal Bozuklukların Tanisal ve İstatistiksel Sinıflandırma Elkitabının (DSM)'in dördüncü basısında TYB'den ilk defa basska türlü adlandırlamayan yeme bozukluklarının altında bahsedilse de elkitabının en son yayımlanan beşinci basısında "Beslenme ve Yeme Bozuklukları" altında ayırıcı kriterleriyle birlikte ayrı bir yeme bozukluğu olarak tanımlanmıştır (Anon., 2010; Anon., 2011; Anon., 2013; Kristeller, 2014; Miller, 2017). Türk popülasyonunu kapsayan çalş̧malar TYB'nin Türk toplumunda en yaygin olarak karşılaşılan yeme bozukluğu olduğunu göstermektedir TYB'nin toplumda görülme sıklı̆g yapılan çalışmalara göre \%0.7 ile \%6.6 arasında değişmektedir. Tahmin edilebileceği üzere TYB obez kişilerde (\%8) daha sik gözlemlenmektedir (Turan vd., 2015).

Yine bu karşılıklardan belki de daha güncel olanı zombi yeme (zombie eating)'dir. Teknoloji çağının sonuçlarından biri denebilecek Zombi yeme, ekranlara bakarken yemek yemeyi ifade etmektedir ve günümüz toplumunda oldukça yaygındır. Amerikan yiyecek markası Snack Factory ${ }^{\circledR}$ Pretzel Crisps ${ }^{\circledR}$ aracillğı ile OnePoll Araştırma Şirketi tarafindan 2000 Amerikalı katıllımcı ile gerçekleştirilen ve katılımcıların yeme alışkanlıklarını gözlemleyen çalışmada popülasyonun \%91'inin yemek yerken telefon, televizyon, tablet ve bilgisayar gibi ekranlar ile meşgul olduğunu rapor edilmiştir. Dahası bu kişilerinde \%49'u bu tutumlarının düzenli olarak tanımlamıştır. Yine söz konusu 2000 kişinin \%86's1 ne ve neyi ne kadar yediklerini unutacak kadar ekran ile meşgul olduklarını belirtmiştir. Ek 
olarak yakın zamanda çocuklar ve genç yetişkinler arasinda ekrana bakma süresi ve beslenme alışkanlıkları arasındaki bağlantıyı inceleyen bir araştırma katılımcıların \%87.5'inin günlük bazda ekran başındayken en az bir öğün veya atıştırmalık yiyecek tükettiğini göstermiştir. Özellikle genç yetişkinlerin günlük kalori alımının neredeyse yarısının $(\% 42,3)$ ekran başında gerçekleştiği rapor edilmiştir (Ericson, 2020; Gervis, 2020; Hanh ve Cheung, 2015; Jensen vd., 2020; Pearson vd., 2017).

\section{Beslenmede Farkındalığın Kişi Üzerinde Etkileri}

Kısaca, gida üzerinde kontrolsüzlük hissinin sıklıkla karşılaşıldığı TYB ve odağın ekranlarda olduğu zombi yemenin de dahil olduğu farkında olmadan yeme, farkındalı̆ı̆n gereklilikleri olan dikkati şimdideki gidaya ve beslenmeden uzak, dolayısıyla farkındalığım sunduğu faydalar olarak bilinç eylemlerinin, kişinin çevreye ve kendine dair farkındalığının artması, geçmiş ve geleceğin yarattığ stresin azaltılması ve en önemlisi anın keyfine varmanın önündeki engel şeklinde sunulmaktadır. $\mathrm{Bu}$ şekliyle beslenmede farkındalığın andaki duyuma ve deneyime odaklanması görünürde gidanın ve beslenmenin öteki, daha teknik kısmını görmezden gelmeye denk düşmektedir. Gıdaların kalori, karbonhidrat, yağ veya protein içeriğinin ve bu içeriklerin diyetlerin kapsamında olduğu gibi beden üzerindeki uzun vadeli sonuçlarının değerlendirilmesinin söz konusu deneyim ile çok az ilgisi vardır. Öyle ki beslenmede farkındalı̆̆ın duygu regülasyonundaki ve psikolojik iyi olma hali üzerinde olumlu etkisi bilimsel olarak gösterilebilse de farkındalığın kilo vermek gibi amaçlarla kullanılabilmesi tartışmalıdır (Anon, 2020: Kidwell vd., 2015; Olson and Emery, 2015; Pintado-Cucarella ve Rodríguez-Salgado, 2016).

Beslenmede farkındalık uygulamalarında mevcut trendler değerlendirildiğinde kilo vermek temel amaç olarak görülmemektedir. Yine de beslenmede farkındalı uygulamaları gerçekleştiren kişilerde kilo vermek beklenen bir sonuçtur. Bağlı olarak 2015 yllında farkındalık ve kilo verme arasındaki bağı araştıran 19 çalışmanın sistematik incelemesinde bu çalıssmaların 13 tanesinde farkindalik uygulamalarından faydalanan katılımcılarda önemli kilo kayıpları gözlenmiştir. Lakin söz konusu çalışsma farkındalık ve kilo verme arasında doğrudan bilimsel bir bağ belgelenemediği ve gelecek çalışmalara ihtiyaç duyulduğu vurgulanmıştır (Olson ve Emery, 2015). Yine 2017 yllinda Cambridge Üniversitesince yayımlanan makalede incelen obez popülasyonu içeren 16 çalışmanın 8 'inde kilo kaybi görüldügüu, ek olarak sadece 3 tanesinde istatistiksel anlamda ciddi kilo kayb1 gözlemlendiği belirtilmiştir. Bununla birlikte farkındalığın sadece kilo vermek için değil, gerektiğinde kilo almak içinde kullanılabildiğini göstermiştir (Kidwell vd., 2015). Sonuç olarak her ne kadar ortaya yeterli bilimsel bağ konamamış olsa da farkındalığın beslenmede tutumlar üzerinde etkili olabileceği ve beslenmede farkındalık ile kilo vermek veya almanın beslenmede farkındalık kavraminin ve tekniklerinin psikolojik ve fizyolojik açlık işaretlerine dikkat etmek, yemek yerken gidanın bedende duyulara ve duygulara hitabinı takip etmek dikkat etmeyi gerektirmesini kapsamasıyla yakından ilişkili olabileceği görünmektedir (Abdul Basir vd., 2021; Dalen vd., 2010; Dunn vd., 2018; Gidugu ve Jacobs, 2019; Hudnall, 2019; Lofgren, 2015; Mantzios ve Wilson 2015 ve 2017; Tronieri vd. 2018). Obez popülasyon haricinde klinik dışındaki popülasyon üzerinde yapılan bir çalışmada sekiz haftalık müdahale şeklinde sunulan beslenmede farkındalı̆̆ın bilişsel esnekliği arttırdığ1 ve bu şekliyle kompülsif yemeyi azalttığ1 not edilmiştir (Janssen vd., 2018) ki bu yine beslenmede farkındalı̆̆ı beslenme alışkanlıklarının değişimi ve kilo kontrolü üzerindeki etkisini çözmek için anahtar niteliğinde olabilir.

\section{Beslenmede Farkındalığı Geliştirme Amaciyla Kullanilan Uygulamalar}

Beslenmede farkındalığı çeşitli yollar ile geliştirilebilir. $\mathrm{Bu}$ bağlamda farkındalık meditasyonları veya programlarını, bunların bir parçası olarak beslenmeye uygulanabilir; MBEAT gibi doğrudan beslemede farkındalığ1 amaçlayan programlara veya da yemek bazında olmak üzere mini meditasyon denilebilecek uygulamalara başvurulabilir. 
Warren ve meslektaşlarının (2017) incelemiş olduğu çalışmalarda, beslenmede farkındalığ arttırmak amacıyla MBCT gibi genel farkındalığ arttırma uygulamaları düşünüldüğünde doğrudan beslenmede farkındalıkla bağıntılı olarak 90'ların sonunda Kristeller ve Hallet tarafindan geliştirilen MB-EAT programı gelmektedir. Kristeller'in ifadesiyle programin temel amac1 süper boy porsiyonlarla yaşadığımız dünyada odağı miktardan, kaliteye çekmektir. Böylece küçük porsiyonlardan maksimum verimi almak amaçlanır. MB-EAT programı, beslenmede farkındalığ1 artırmak ve farkında olmadan beslenmenin etkilerini azaltmak için tasarlanmıştır. Beslenmede farkındalık egzersizleri, Özellikle fiziksel açlık ve tokluk ipuçlarına, genel gıda alımına ve aşırı yemenin fiziksel, bilişsel, sosyal-çevresel ve duygusal tetikleyicilerine odaklanır. Program boyunca genel farkındalık ve rehberli yeme meditasyonlarının yanında kişilerin gün için rahatlikla uygulayabilecekleri mini meditasyonlar öğretilir (Choi ve Lee, 2020; Fletcher, 2014; Kristeller vd., 2014 ve 2021).

Mini meditasyonlar kapsamında MB-EAT programının mucitlerinden Kristeller'dan (2015) örnek verilebilir (Çizelge 2). Söz konusu egzersiz, kişilerin tat duyusuna odaklanmak için tasarlanmıştır. Egzersizdeki amaç diğer bütün farkındalık uygulamaları ile ortak olarak anın tadını çıkarmak ve ek olarak küçük porsiyonlarda yemek yeme keyfini maksimum seviyeye çıkarmaktır. Bu noktada kişilerin bedenlerine de dikkati artacağından sezgisel yeme kavramıyla da uyumlu olarak açlık, tokluk hissine karşı da daha duyarlı olması beklenecektir.

Çizelge 2. Örnek beslenmede farkındalık egzersizi

Bir dahaki yemek yiyişinizde önünüzdeki gıdaların sadece birine odaklanın, seçeceğiniz gıdanın kompleksten ziyade sade bir aromaya sahip olması egzersizi daha efektif kilacaktır.

- İlk 1sırıkta seçtiğiniz gidanın tadına odaklanın.

- Sonra, ikinci yudumdayken çiğneme sırasında gıdanın tadının nasıl değiştiğine odaklanın ve kendinize sorun: Çiğneme süreci devam ettikçe gıdadan aldığınız keyif arttı mı azaldı mı yoksa aynı mı kaldı? Hangi noktadan itibaren gıdanın tadı kaybolmaya başladı?

- Sonraki yudumlarınızda da aldığınız her yudumda tadın nasıl değiştiğine odaklanmaya devam edin.

Bununla birlikte beslenmede farkındalık uygulamaları beslenmenin sadece gida tüketim kısminı kapsamak zorunda değildir. Bu konuda Nelson (2017), Kabat-Zinn'in rehberliğinde gerçekleştirilen üzüm yemeye dair meditasyonu örnek verir (Çizelge 3). Söz konusu meditasyonda gıdanın tadının haricindeki duyulara hatta bilişe de hitab1 söz konusudur. Bu açıdan söz konusu meditasyon beslenmenin, sadece yemenin ötesinde daha kapsamlı bir süreç olduğunu vurgulamaktadır.

\section{Beslenmede Farkındalığın Ölçülmesi}

Yapılan çalışmalarda kişilerin beslenmede Farkındalıklarını ölçmek için kullanılan araçlardan Framson ve meslektaşları tarafindan 2009 yilında hazırlanan Beslenmede Farkındalık Anketi (The Mindful Eating Questionnaire, MEQ) literatürde kavramı doğrudan ölçen tek ölçüt konumundadır.
Anket, dörtlü likert ölçeği şeklinde düzenlenmiş 28 madde ve 5 alt faktörden oluşmaktadır. Söz konusu alt faktörler, disinhibisyon (disinhibition), farkındalık (awareness), diş etkenler (external cues), duygusal cevap (emotional response) ve dikkat dağılması (distraction) şeklindedir. Söz konusu çalışmada ve bunun üzerine ileriki çalışmalarda, anketin güvenilirliğinin (Cronbach Alpha skoru) istatistiki olarak kabul edilebilir seviyede olduğu gözlemlenmiştir. Bu çalışmalara Köse ve Arkadaşları tarafindan 2016 yılinda MEQ'in Yeme Farkındalı̈ı̆ Ölçeğ adı altında Türkçe uyarlaması da dahildir. Bununla birlikte anketin Türkçe çevirisi, Türk kültürüne uygun olarak 7 alt-faktör altında toplanmış (Disinhibisyon, Duygusal Yeme, Yeme Kontrolü, Odaklanma, Yeme Disiplini, Farkındalık ve Enterferans) ve madde sayıs1 30'a çıkarılmışır (Köse, 2016 ve 2020; Köse ve Ark., 2016; Köse 
ve Çıplak, 2020). Bu ölçek kullanılarak Kuseyri ve Kızıltan (2019) tarafindan Başkent Üniversitesi Sağlık Bilimler Fakültesi üniversite öğrencileri üzerinde gerçekleştirilen çalışmada katılımcıların yeme farkındalığ1 ve beden kütle indeksleri (BKI) arasinda istatistiki olarak önemli negatif bir korelasyon bulunmuştur. Aynı doğrultuda obez olarak sinıflandirılan kişilerde yeme farkındalığının daha düşük olduğu not edilmiştir.
Ayrıca bir not olarak Durukan ve Gül tarafindan (2019) yapılan çalışma MEQ'in Türkçe çevirisi ile BKİ arasında istatistiki olarak önemli bir bağ bulmuştur (p:.00, P <0.05). Söz konusu bulgu, anketin güvenilirliğini arttırmanın yanında yazarlar tarafindan da not edildiği üzere beslenmede farkındalığın uzun süreli kilo kontrolünde önemli bir etken olabileceğine işaret etmektedir.

Çizelge 3. Örnek rehberli beslenmede farkındalık egzersizi

\section{Üzümü yemeden önce:}

- Üzümü elinize alın ve hemen ağzınıza atmadan hemen önünüzde tutun.

- Bir an için dünyaya ilk defa geldiğinizi, dünyada hiçbir deneyiminiz olmadığını ve her şeyin sizin için yeni olduğunu varsayın. Dolayısıyla kendinizi deneyimden, bilgiden ve bunlardan kaynaklanan yargı, korku ve beklentilerden arındırmaya çalısın.

- Bu süreçte derin nefesler alarak sakinleşin ve bütün odağınızı elinizdeki üzüme getirin.

- Şimdi, üzümü elinizde tutarken önce ağırlığını inceleyin.

- Yüzeyini inceleyerek hem yüzeyinin görüntüsünü hem de hissiyatına odaklanın.

- Üzümü burnunuza yaklaştırarak koklayın.

- Üzümü parmaklarınız arasında dolaştırarak, ortaya çıkan sese dikkat edin, elinizden kayan dokusuna dikkat etmeye çalışın.

- Bu sırada üzüme dair deneyimlerinizin, duyumlarınızın ne olduğu ve bu sürede hislerinizin nasıl değiştiğini fark etmeye çalışın.

Üzümü yerken:

- Üzümü yemeden hemen önce bir iki saniye için dudaklarınızın arasında tutarak bedeninizde olan değişimleri gözlemleyin.

- Üzümü ağzınıza aldığınızda hemen çiğnemeyerek bir süre ağzınızda dolaştırın ve tadıyla yine bedeninizin verdiği tepkiye odaklanın.

- Üzümden ilk başta küçük bir 1sırık alıp sonrasında çiğnerken bu ilk an ile çiğnemenin devamında üzümün duyularınızdaki ve düşüncelerinizdeki değişime dikkat edin. Tat çiğneme süresince nasıl değişti? Üzüm açlık ve tokluk hissinize nasıl etki etti?

- Meditasyonun etkisini maksimuma çıkarmak için üzümü yutmadan önce iyice çiğnediğinizden emin olun.

Üzümü yedikten sonra:

- Üzümü yuttuktan sonra gözlerinizi bir süre için kapatarak bu deneyimin sizde yarattığ1 değişime odaklanın.

\section{SONUÇ}

Yapılan araştırma sayısı ve bu çalışmalarda işaret edilen bilimsel öğeler, farkındalı̆ı̆n insan hayatına olan istatiksel olarak önemli etkisini göstermektedir. Farkındalık insanların depresyon, kronik kayg1 gibi klinik problemlerin yanında problem çözme, duygu regülasyonu gibi sıklıkla karşılaşılan ruhsal ve bilişsel sorunlarla baş etmesine yardımcı olarak kişilerin daha ana odaklı ve bilinçli şekilde yaşamasına yardımcı olmuştur (Deliperi vd., 2011; Desbordes vd., 2012; Warren vd., 2017). Farkındalık üzerine yapılan çalışmalarla 
kıyaslandığında beslenmede farkındalık çalışmalarının sayıca oldukça az olduğu gözlemlenebilir. Bu çalışmalara bakarak ilk olarak incelenen makaleler, beslenmede farkındalık bir parçası olmak üzere farkındalığın insanların yeme davranışlarını değiştirebileceğine dair makul kanitlar sunmaktadır. Bununla birlikte beslenmede farkındalık uygulamalarının kişilerin ruhsal sağlıklarına olumlu etkide bulunduğu not edilmiş, kişiler genel farkındalık ve beslenmede farkındalık uygulamalarının gıda seçimlerine etkisi olduğunu belirtmiştir. Maalesef beslenmede farkındalığın kilo verme üzerine etkisini inceleyen çalışmaların sonuçları çelişkilidir. Ek olarak beslenmede farkındalık ile ilgili çalısmaların çoğunluğunun obez kişiler üzerinde yapılması sonuçları topluma genelleyebilmeyi zorlamaktadır. Türk popülasyonunu kapsayan çalışmalarda benzer şekilde bilgilendirici olsa da beslenmede farkındalık ve Türk toplumu arasındaki muhtemel bağları araştırmak için gelecek araştırmalar önem arz etmektedir. Diğer bir önemli nokta da ölçüm aletlerinin çeşitlendirilmesi gerekliliğidir. Literatür incelendiğinde Türkiye'de ve Dünya genelinde MEQ beslenmede farkındalık için en sık başvurulan ölçüt konumundadır. Bu ölçütün kişilerin raporlarına dayanması yanlılığa (bias) açık olmas1 anlamina gelmektedir (Baer vd., 2006). Buna bağlı olarak kişilerin beslenmede farkındalık seviyelerini anlamak için söz konusu anket ve gelecektekiler nörobilimsel çalışmalar gibi tamamlayıcı fiziksel veriler ile desteklenmelidir.

Bu çalışmayla da gelecekte yapılabilecek çalışmalar için Türk beslenme ve psikoloji literatürüne katk1 sağlamak amaçlanmıştır. Ayrıca bu çalışmayla modern yaşamla artan farkında olmama halinin beslenme üzerindeki etkisi gösterilmeye çalışılarak, gelecekte yine bu alanda yapılacak çalışmaların ve uygulamalarının önemi vurgulanmak istenmiştir.

\section{KAYNAKLAR}

Abdul Basir, S. M., Abdul Manaf, Z., Ahmad, M., Abdul Kadir, N. B., Ismail, W. N. K., Mat Ludin, A. F., Shahar, S. (2021). Reliability and Validity of the Malay Mindful Eating Questionnaire (MEQM) among Overweight and Obese Adults. Int J
Environ Res Public Health, 18(3), 1021., doi:10.3390/ijerph18031021

Anon (2010). Mindful Eating Discovering a Better Relationship with Your Food, University of Wisconsin Integrative Medicine Department of Family Medicine.

Anon (2011). Diabetes: Mindful eating, University of Michigan, Comprehensive Diabetes Center.

Anon (2013). Diagnostic and statistical manual of mental disorders, Am Psychiatr Assoc, 5th edition (DSM-IV), text rev. Washington, DC.

Anon (2020). 8 steps to mindful eating, Harv Health. https://www.health.harvard.edu/stayinghealthy/8-steps-to-mindful-eating. (Erişim tarihi: 25.07.2021)

Baer R. A., Smith G. T., Hopkins J., Krietemeyer J., Toney L. (2006). Using self-report assessment methods to explore facets of mindfulness. Assess; 13(1): 27-45.

Burton, E. T., Smith, W. A. (2020). Mindful Eating and Active Living: Development and Implementation of a Multidisciplinary Pediatric Weight Management Intervention. Nutr, 12(5), 1425. https://doi.org/10.3390/nu12051425

Choi, S., Lee, H. (2020). Associations of mindful eating with dietary intake pattern, occupational stress, and mental well-being among clinical nurses. Perspect Psychiatr Care, 56(2), 355-362. https://doi.org/10.1111/ppc.12441

Compton, W. C., Hoffman, E. (2018). Positive psychology: The science of happiness and flourishing (3rd ed.). Thousand Oaks, Canada: SAGE Pub.

Dalen, J., Smith, B. W., Shelley, B. M., Sloan, A. L., Leahigh, L., Begay, D. (2010). Pilot study: Mindful Eating and Living (MEAL): weight, eating behavior, and psychological outcomes associated with a mindfulness-based intervention for people with obesity. Elsevier, 18:260-264

Desbordes G., Negi L. T., Pace T. W., Wallace B. A., Raison C. L., Schwartz E. L. (2012). Effects of mindful-attention and compassion meditation training on amygdala response to emotional stimuli in an ordinary, non-meditative state. Front 
Hum Neurosci

doi:10.3389/fnhum.2012.00292

Dunn, C., Olabode-Dada, O., Whetstone, L., Thomas, C., Aggarwal, S., Nordby, K., Thompson, S., Johnson, M. (2018). Mindful Eating and Weight Loss, Results from a Randomized Trial, J Fam Med Community Health, 5(3): $1152,7 \mathrm{~s}$.

Durukan, A., Gül, A. (2019). Mindful eating: Differences of generations and relationship of mindful eating with BMI. Int J Gastronomy Food Sci, 18, p.100172.

Erickson, M. (2020). Eating while distracted: How to break the habit of 'zombie eating'. https://www.jdnews.com/news/20190919/eati ng-while-distracted-how-to-break-habit-ofzombie-eating (Erişim Tarihi: 18.04.2021)

Fletcher, M. (2014). Starting a Mindful Eating Practice, The Center for Mindful Eating. www.thecenterformindfuleating.org, (Erişim tarihi: 22.06.2021)

Framson, C., Kristal, A. R., Schenk, J. M., Littman, A. J., Zeliadt, S., Benitez, D. (2009). Development and validation of the mindful eating questionnaire. J Ame Diet Assoc, 109(8), 14391444.

https://doi.org/10.1016/j.jada.2009.05.006

Gervis, Z. (2020). 88 percent of Americans are zombie eaters who can't munch without staring at a

https://www.swnsdigital.com/2019/07/88-

percent-of-americans-are-zombie-eaters-whocant-munch-without-staring-at-a-screen/

(Erişim Tarihi: 18.04.2021)

Gidugu, V., Jacobs, M. L. (2019). Empowering individuals with mental illness to develop healthy eating habits through mindful eating: results of a program evaluation, Psychol Health Med, 24 (2):177-186

Grecucci, A., Pappaianni, E., Siugzdaite, R., Theuninck, A., Job, R. (2015). Mindful Emotion Regulation: Exploring the Neurocognitive Mechanisms behind Mindfulness. Biomed Res Int, 2015, 670724. doi:10.1155/2015/670724
Hanh, T. N., Cheung, L. (2015). Savor: Mindful Eating, Mindful Life. HarpenCollins Pub, New York (NY).

Hong, P., Lishner, D., Han, K., Huss, E. (2011). The Positive Impact of Mindful Eating on Expectations of Food Liking. Mindfulness, 2(2), 103-113. https://doi.org/10.1007/s12671-0110048-3

Hudnall, M. (2019). Mindful Eating in Nutrition Counseling for Eating Behaviors: What Research Suggests, Today's Dietitian, The Mag Nutr Prof, 18.

Ives-Deliperi, V. $\quad$ L., Solms, M., Meintjes, E. M. (2011) The neural substrates of mindfulness: an fMRI investigation. Soc Neurosci, 6, 231-242

Janssen, L., Duif, I., van Loon, I., de Vries, J., Speckens, A., Cools, R., Aarts, E. (2018). Greater mindful eating practice is associated with better reversal learning, Sci Rep, 8(1), https://doi.org/10.1038/s41598-018-24001-1

Jensen M. L., Dillman Carpentier, F., Corvalán C. (2020). Screen time and eating during screen time: associations with dietary intake in children and adolescents, 20 January 2020, preprint (Version 1) Res

[https://doi.org/10.21203/rs.2.21352/v1]

Kabat-Zinn J (1991). Full Catastrophe Living. New York, N.Y, Dell Pub.

Kerin, J., Webb, H., \& Zimmer-Gembeck, M. (2019). Intuitive, mindful, emotional, external and regulatory eating behaviours and beliefs: An investigation of the core components. Appetite, Elsevier, 132, 139-146. https://doi.org/10.1016/j.appet.2018.10.011

Kidwell, B, Hasford, J.,

Hardesty, D. (2015). Emotional ability training and mindful eating. J Marketing Res LII, 105-119

Köse, G. (2016). Yeme Farkındalı̆̆1 Ölçeği. TOAD Türkiye Ölçme Araçları Dizini. https://toad.halileksi.net/olcek/yeme-

farkindaligi-olcegi-yfo-30 (Erişim tarihi: 17.06.2021)

Köse, G. (2020). Can Mindful Eating Help Us When We Struggle With Eating? Mindful Eating Replaces Diets. Turk J Sport Exercise, 22 (1): 72-77. 
Köse, G., Çıplak, E. (2020). Mindful eating questionnaire: eating control, emotional eating and conscious nutrition trio, Prog Nutr, Vol. 22, N. 2,7 .

Köse, G., Tayfur, M., Birincioğlu, İ., Dönmez, R. A. (2016). Yeme Farkındalı̆̆ Ölçeğini Türkçeye Uyarlama Çalışması. Bilişsel Davramış̧ı Psikoterapi ve Arasturmalar Derg, 3(3): 125-134. doi:10.5455/JCBPR.250644

Kristeller J. (2015). The Joy of Half a Cookie. New York, N.Y., Perigee

Kristeller, J. L., Epel, E. (2014). Mindful eating and mindless eating: The science and the practice, in A. le, C. T. Ngnoumen, \& E. J. Langer (Eds.), The Wiley Blackwell handbook of mindfulness, s. 913-933. Wiley Blackwell. https://doi.org/10.1002/97811182948 95.ch47

Kristeller, J. (2021). Know Your Hunger. https://www.balancedlivingpsychology.com/me dia-podcasts-2/mindful-eating-by-mb-eat-

founder-jean-kristeller/ (Erişim tarihi: 29.07.2021)

Kristeller, J., Wolever, R. Q., Sheets, V. (2014). Mindfulness-Based Eating Awareness Training (MB-EAT) for Binge Eating: A Randomized Clinical Trial. Mindfulness, 5, 282-297. https://doi.org/10.1007/s12671-012-0179-1

Kuseyri G., Kiziltan G. (2019). Universite Ögrencilerinde Yeme Farkındalığ ve Sezgisel Yeme Davranışının Beslenme Durumu Uzerine Etkisi, Baskent Unv Saghk Bulım Fakul Derg, 4(3), s. 202-2019.

Langer, E. J., Moldoveanu, M. (2000). The construct of mindfulness. J Soc Issues, 56(1), s. 19. https://doi.org/10.1111/0022-4537.00148

Lofgren, I. E. (2015). Mindful Eating: An Emerging Approach for Healthy Weight Management, Ame J Lifestyle Med, 9(3): s. 212-216.

Mantzios, M., Wilson, J. C. (2015). Mindfulness, Eating Behaviours, and Obesity: A Review and Reflection on Current Findings. Curr Obes Rep, 4(1), s. 141-146. https://doi.org/10.1007/s13679-014-0131-x
Miller C. K. (2017). Mindful Eating With Diabetes. Diabetes Spectrum: Am Diabetes Assoc, 30(2), s. 89-94. https://doi.org/10.2337/ ds16-0039

Nelson J. B. (2017). Mindful Eating: The Art of Presence While You Eat. Diabetes Spectrum: Am Diabetes Assoc, 30(3): 171-174. https://doi.org/ $10.2337 / \mathrm{ds} 17-0015$

Pearson, N., Griffiths, P., Biddle, S., Johnston, J., McGeorge, S., Haycraft, E. (2017). Clustering and correlates of screen-time and eating behaviours among young adolescents, BMC Pub Health, 17(1), https://doi.org/10.1186/s12889-017-4441-2

Pintado-Cucarella, S., Rodríguez-Salgado, P. (2016). Mindful eating and its relationship with body mass index, binge eating, anxiety and negative affect, J Behav Health Soc Issues, 8, s. 1924

Powell, A. (2018). When science meets mindfulness. Harv Gaz: (Erişim tarihi: 26.07.2021)

Schuman-Olivier, Z., Trombka, M., Lovas, D. A., Brewer, J. A., Vago, D. R., Gawande, R., Dunne, J. P., Lazar, S. W., Loucks, E. B., Fulwiler, C. (2020). Mindfulness and Behavior Change. Har Rev Psychiatr , 28(6):371-394. https://doi.org/ 10.1097/HRP.0000000000000277

Shapero, B. G., Greenberg, J., Pedrelli, P., de Jong, M., Desbordes, G. (2018). MindfulnessBased Interventions in Psychiatry. Focus ( $\mathrm{Am}$ Psychiatr Pub), 16(1): 32-39. https://doi.org/10.1176/appi.focus.20170039

Tronieri, J., Wadden, T., Pearl, R., Berkowitz, R., Alamuddin, N., Chao, A. (2020). Mindful Eating, General Mindful Awareness, and Acceptance as Predictors of Weight Loss. Mindfulness, 11(12): 2818-2827. https://doi.org/10.1007/s12671020-01493-5

Turan, S., Poyraz, C. A., Özdemir, A. (2015). Binge Eating Disorder/ Tikanircasina Yeme Bozukluğu. Curr Approaches Psychiatr, 7(4): 419. https://link.gale.com/apps/doc/A558921391/A ONE? $=$ anon $\sim 13 \mathrm{~b} 44 \mathrm{af1} \&$ sid $=$ googleScholar\&x $\mathrm{id}=\mathrm{b} 030 \mathrm{c} 6 \mathrm{e} 5$ 
Warren, J., Smith, N., Ashwell, M. (2017). A structured literature review on the role of mindfulness, mindful eating and intuitive eating in changing eating behaviours: Effectiveness and associated potential mechanisms. Nutr Res
Rev, 30(2):

272-283.

S0954422417000154 doi:10.1017/ 